\title{
ETILÔMETRO: UM TEMA CONTEMPORÂNEO COM POTENCIAL INTERDISCIPLINAR PARA O ENSINO DE CIÊNCIAS
}

\section{JoÃo PAULO CASARO ERTHAL}

Universidade Federal do Espírito Santo

E-mail: jperthal@gmail.com

\section{HEBERT DE AMORIM FOLLI}

Universidade Federal do Espírito Santo

E-mail: hebert.folli@gmail.com

\section{KARLA AGUIAR KURY \\ Pizelli Advogados Associados \\ E-mail: karlakury@gmail.com}

\begin{abstract}
RESUMO
Nos dias atuais, torna-se cada vez mais necessários o ensino e a discussão de conceitos científicos atrelados a tecnologias com repercussão na sociedade. Um equipamento que tem sido destaque nos noticiários é o etilômetro, amplamente utilizado nas operações de fiscalização da Lei Seca. A investigação sobre o funcionamento do etilômetro e a inserção do assunto no ambiente escolar pode auxiliar na discussão e no ensino de tópicos relacionados à Química, Física, Matemática, Biologia e História da Ciência, envolvendo relações entre ciência, tecnologia e sociedade. Pode ainda fomentar atividades de conscientização dos jovens a respeito da ingestão de bebidas alcoólicas e da direção de veículos automotores. Este trabalho apresenta características científicas de diferentes etilômetros e seu potencial interdisciplinar como tema gerador para a apropriação de conceitos de acordo com as orientações de documentos educacionais.
\end{abstract}

PALAVRAS-ChAVE:

Etilômetro; Interdisciplinaridade; Ensino De Ciências.

\section{BREATHALYZER: A CONTEMPORARY THEME WITH INTERDISCIPLINARY POTENTIAL FOR SCIENCE EDUCATION}

\begin{abstract}
In today's world, it is becoming increasingly important the teachings and discussions of the links between technology and how it can have an impact in our society. One device that has been making the news lately is the breathalyzer, currently being used to enforce the "Lei Seca" Operation. The study of how the breathalyzer works, if added into the school curriculum, can help students expand their understanding of many classes such as Chemistry, Physics, Math, Biology and History, helping close the gap between science, technology and society. Most importantly, it can also help students take a leadership role in the prevention and the dangers of Drinking and Driving. This study takes a
\end{abstract}


look at the scientific characteristics of different types of breathalyzers and its potential addition as an interdisciplinary course while still following the parameters of educational guidelines.

\section{KEYWORDS:}

Breathalyzer; Interdisciplinarity; Science Education.

\section{INTRODUÇÃO}

Muitas são as críticas feitas ao ensino de ciências no Brasil. Talvez a mais contundente seja a falta de relação entre os conteúdos discutidos em sala de aula e a realidade vivenciada pelo estudante em seu cotidiano. A formação na educação básica não tem sido eficaz em fazer com que o estudante compreenda os conteúdos escolares a partir de tecnologias atuais, tão presentes e marcantes na vida desses sujeitos, uma vez que essas raramente estão presentes nas discussões em sala de aula.

Desde o século XX, autores como Krasilchik (1992) defendem que o ensino de ciências deveria estar direcionado à discussão e solução de problemas cotidianos, além de conter uma preocupação especial para a formação de uma base científica sólida agregando melhorias na qualidade de vida dos estudantes.

Devido à crescente dependência tecnológica da sociedade, intensifica-se a necessidade de todos se apropriarem de conhecimentos científicos, básicos ou avançados, seja para utilizá-los em suas profissões, na resolução prática de atividades com aparelhos eletroeletrônicos, e seus inúmeros aplicativos, ou na interpretação de situações que possam vir a vivenciar. Entretanto, essa apropriação de competências não vem acontecendo e é denotada pelo grande número de usuários que, simplesmente, consomem o que as tecnologias oferecem sem conseguir compreender o funcionamento dessas, ou utilizar tais recursos para resolução de problemas.

Com isso, o processo de formação dos estudantes deveria fomentar atividades e ações que auxiliassem a despertar a curiosidade e a formar cidadãos com um posicionamento crítico acerca do funcionamento de equipamentos que fazem parte do seu dia a dia. Philipe Perrenoud (2000), no livro "10 novas competências para 
ensinar", apresenta uma lista de competências essenciais para uma atuação de qualidade dos professores, sendo que dentre elas está a necessidade de se utilizar e discutir novas tecnologias em sala de aula.

De acordo com as Diretrizes Curriculares Nacionais "compreende-se o conhecimento como uma produção do pensamento pela qual se apreende e se representam as relações que constituem e estruturam a realidade" (BRASIL, 2013, p. 161). Seguindo essa linha de pensamento, o ensino de ciências tem procurado, mesmo que timidamente, se mostrar cada vez mais contextualizado, buscando envolver Ciência, Tecnologia e Sociedade (CTS). Um tema em voga atualmente, que se encaixa nessa perspectiva, é a fiscalização de condutores de veículos automotores em relação ao nível de álcool possivelmente ingerido, realizada com o uso do etilômetro. A contextualização do funcionamento e da utilização desse aparato possibilita ampla discussão de conteúdos relacionados aos temas estruturadores contidos nos Parâmetros Curriculares Nacionais (PCN) em diversas áreas do conhecimento (BRASIL, 1999).

Na televisão, nos jornais e na internet são frequentes as reportagens tratando sobre as intervenções policiais conhecidas como "Operação Lei Seca", em referência à Lei no 11.705/08 que fez alterações no Código de Trânsito Brasileiro (CTB) (BRASIL, 1997). Inúmeras são as campanhas dos órgãos reguladores de trânsito para conscientização da sociedade sobre o assunto. Entretanto, essas informações praticamente não são trazidas a tona no ambiente escolar, o qual poderia ter um papel importante para fomentar discussões e estudos sobre o tema, potencializando os alunos para a disseminação do assunto na sociedade.

A esse turno, o etilômetro, conhecido popularmente como bafômetro, é o principal aliado da fiscalização a respeito do uso de bebidas alcoólicas por condutores 
de veículos automotores, contudo a legislação possibilita outros meios de prova da embriaguez, como vídeo ou testemunhas.

A blitz policial faz uso do etilômetro para apurar se o condutor de veículos automotores consumiu bebidas alcoólicas, mas ela não serve apenas para aplicar multas e penalizar os motoristas. Seu objetivo é, também, realizar um trabalho preventivo e educativo aos condutores para que esses não ingiram bebidas alcoólicas quando forem dirigir. Nessas ações, o policial militar deve abordar o motorista solicitando seus documentos juntamente com sua carteira nacional de habilitação. Uma vez que esse procedimento é efetuado, o motorista é conduzido à realização do teste do etilômetro, sendo convidado a assoprar a piteira do equipamento. Feito o teste, se o condutor não apresentar taxa de álcool no organismo ele é liberado.

Caso esteja sob a influência de álcool, houve infração do artigo 165 do CTB e foi cometida uma infração gravíssima, com penalidade de multa e suspensão do direito de dirigir durante um ano, bem como medida administrativa de retenção do veículo e recolhimento do documento de habilitação. Importante ressaltar que no objetivo de aumentar o rigor da fiscalização, por meio da Lei n. 13.281/2016, inseriu-se o artigo 165-A ao CTB, por meio do qual o simples fato de se recusar a fazer o teste de alcoolemia já configura infração com as mesmas penalidades do artigo 165 (BRASIL, 1997).

De forma mais grave, se o condutor apresentar uma taxa igual ou superior a 6,0 decigramas de álcool por litro de sangue, ou 0,3 miligramas de álcool por litro de ar expelido, fica configurado crime, conforme artigo 306 do CTB, cuja penalidade é a detenção de seis meses a três anos, além da multa e da proibição do direito de conduzir veículos automotores (BRASIL, 1997). Em dezembro de 2017 entrou em vigor a lei n. 13.546, a qual dispõe sobre crimes cometidos na direção de veículos automotores, e incluiu dispositivos para Homicídio Culposo e Lesão Corporal Culposa 
se o agente que conduz veículo automotor estiver sob a influência de álcool. Tais crimes têm como penalidade reclusão de cinco a oito anos e de dois a cinco anos, respectivamente, além da suspensão ou proibição do direito de dirigir em ambos os casos (BRASIL, 2017).

No Estado do Rio de Janeiro, desde o início da "Operação Lei Seca", em 19 de março de 2009, 2,4 milhões de condutores foram abordados em mais de 17 mil operações, nas quais, cerca de, 167 mil motoristas apresentavam sinais de embriaguez e tiveram suas carteiras recolhidas (GOVERNO DO RIO DE JANEIRO, 2017).

São recorrentes as reportagens sobre motoristas flagrados dirigindo embriagados. A falta de consciência de muitos motoristas faz com que atrelem álcool com condução de veículos automotores, e esse problema existe desde que os automóveis surgiram. Atuando, principalmente no sistema nervoso central, a bebida alcoólica é considerada depressora por causar efeitos colaterais no consumidor, ocasionando desde mudanças de humor até perda total de consciência.

De acordo com dados do Departamento de Trânsito do Estado do Rio de Janeiro, o Brasil é o quarto país com mais mortes no trânsito no mundo. Segundo os dados do Ministério da Saúde, o número de mortos em acidentes de trânsito era de 33.105, em 2004, e aumentou drasticamente na década seguinte chegando a 43.780 em 2014 (DATASUS, 2018). Com o intuito de penalizar, obter dados estatísticos e conscientizar, o etilômetro é uma importante ferramenta para diminuição de mortes no trânsito.

Mas afinal, como se dá o funcionamento desse aparelho? Quais são os conhecimentos científicos que foram utilizados para o desenvolvimento dessa tecnologia? Como esse aparelho poderia ser utilizado em sala de aula para discussão de temas relacionados à ciência? Este artigo se propõe a responder essas questões e sugerir discussões em sala numa perspectiva que envolva ciência, tecnologia e sociedade. 


\section{METODOLOGIA}

\subsection{FUNDAMENTAÇÃO TEÓRICA}

A cronologia do consumo de bebidas está relacionada a determinados costumes da sociedade. No estudo da história dos povos antigos, a bebida não pode ser tratada da mesma forma que é vista hoje em dia, pois existem diferentes contextos sociais envolvidos. É possível relacionar aspectos culturais e religiosos de diferentes épocas com o consumo de bebidas, tal como a ingestão de vinho ou infusões de ervas, repletos de simbolismos religiosos, em determinadas cerimônias.

Na Antiguidade, dentre as principais bebidas consumidas estavam a cerveja e o vinho. Já na Idade Média, os Árabes adotaram, na Europa, o processo de destilação, cujo resultado foi o aumento do teor alcoólico das bebidas (SOUZA, 2014).

O consumo dos destilados se tornou a preferência das pessoas a partir da Revolução Industrial. Nos dias atuais, existem centenas tipos de bebidas alcoólicas, sendo a cerveja, o vinho, o saquê, a vodka e a cachaça as mais consumidas mundialmente. Algumas dessas podem conter teores alcoólicos em torno de 88\% como a vodka Balkan, produzida na Bulgária.

O físico e químico francês Joseph Gay-Lussac realizou uma contribuição fundamental para o cálculo do percentual de teor alcoólico das bebidas através de sua lei volumétrica, no ano de 1808. Hoje em dia, o teor alcoólico é medido em uma escala GL (Gay-Lussac), que leva em conta o percentual volumétrico de etanol (álcool etílico anidro) em uma mistura de álcool com água (LEAL et al., 2012).

Ao ingerir uma bebida alcoólica, assim como acontece aos demais nutrientes, o álcool é absorvido no organismo pelo estômago e principalmente pelo intestino delgado. Em seguida ele circula pela corrente sanguínea por todo o corpo humano, sendo eliminados, aproximadamente, dois décimos de gramas de álcool por quilo de massa corpórea a cada hora e, por isso, pessoas magras podem se embriagar em um 
intervalo de tempo bem menor em relação às pessoas obesas. Outro fator condicionante para a embriagues é a ingestão de alimentos, pois o alimento auxilia a diluir o álcool e retê-lo por um determinado período, prolongando o tempo de absorção pelo organismo. Por outro lado, bebidas com dióxido de carbono em sua composição, como os atuais energéticos, são capazes de acelerar esse processo (LEAL et al., 2012).

O fígado é o principal órgão responsável por filtrar esse produto da corrente sanguínea. Ele produz CO2 enquanto gera energia, e também é responsável por outras funções vitais como armazenar e liberar glicose, secretar a bile, produzir proteínas, metabolizar lipídeos, filtrar microrganismos e desintoxicar o organismo, transformando hormônios ou drogas, como o álcool, em substâncias não ativas para que o organismo possa excretá-las. Se o indivíduo ingerir índices elevados de bebidas alcoólicas por um período prolongado, o fígado deixará de realizar funções básicas, parando de gerar energia, e as toxinas irão começar a se acumular no organismo (Doenças do Fígado, 2018).

Uma pequena parcela de álcool também é eliminada pela transpiração e respiração. Nos pulmões ocorrem as trocas gasosas, e parte do álcool presente na corrente sanguínea é eliminado durante essas trocas. Pensando nisso, o médico Francis Edmund Anstie observou, na segunda metade do século XIX, que o álcool era perceptível na respiração, e com isso foram iniciadas pesquisas sobre a possibilidade de testar o teor alcoólico de uma pessoa a partir da respiração. Em 1954, o policial Dr. Robert Borkenstein da polícia do Estado de Indiana, nos Estados Unidos, criou um aparelho capaz de analisar com confiabilidade o teor alcoólico presente na corrente sanguínea, através do álcool exalado na respiração (BREATHALYSERS IN HISTORY, 2018). 
Esse aparelho é denominado etilômetro, um instrumento capaz de medir a concentração de álcool etílico pela análise de ar pulmonar, e seu funcionamento ocorre devido a reação eletroquímica de oxidação e redução.

Tal reação ocorre quando uma substância perde elétrons e outra substância recebe esses elétrons, gerando uma corrente elétrica. O etilômetro possui dois pólos, o ânodo e o cátodo. No ânodo encontra-se a substância que perdeu os elétrons, ou seja, que oxidou, e no cátodo localiza-se a substância que recebeu tais elétrons, logo ela reduziu, originando o termo oxirredução.

Existem alguns tipos de etilômetros de análises qualitativas, nos quais o funcionamento é baseado na mudança de cor do reagente pela oxirredução. Existem também etilômetros que fornecem análises quantitativas que indicam um valor para o grau alcoólico do indivíduo testado, como os modelos utilizados pela polícia no Brasil.

No etilômetro qualitativo, o ar contendo álcool etílico entra em contato com o dicromato de potássio $\mathrm{K}_{2} \mathrm{Cr}_{2} \mathrm{O}_{7}$, que em seu estado natural possui coloração amarelada. Após o contato, o álcool etílico oxida a aldeído e o dicromato de potássio é reduzido a cromo (III), que possui cor verde, ou cromo (II), que possui cor azul. Se o motorista possuir uma quantidade significativa de etanol no organismo, ao assoprar esse tipo de etilômetro, o resultado será a mudança da cor amarela para um verde azulado. O nível de álcool no organismo será determinado pelo tom da cor, pois quanto mais escuro, maior é o nível de embriaguez (BRAATHEN, 1997). A figura seguinte ilustra o funcionamento desse equipamento. 
Figura 1: Mudança na coloração de um etilômetro qualitativo. Fonte: autor.

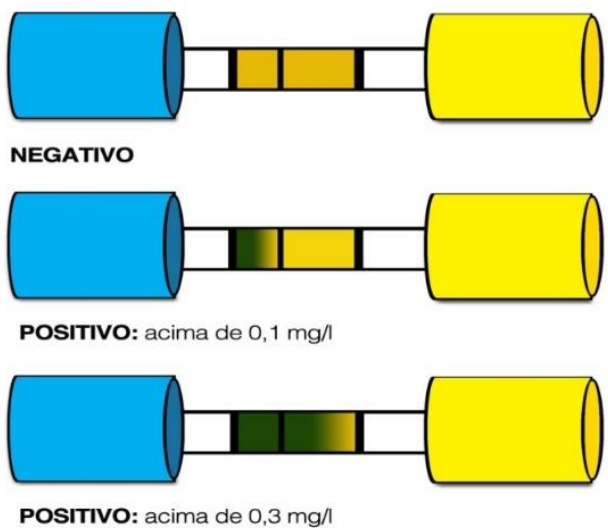

Esse modelo de etilômetro é descartável e é um dispositivo simples de ser reproduzido, uma vez que seu principal componente, o dicromato de potássio, é fácil de ser adquirido.

Dentre os etilômetros quantitativos, destacam-se dois modelos utilizados pela Polícia Rodoviária Federal do Brasil: o Alco-Sensor III e Alco-Sensor IV.

Figura 2: Etilômetro alco-sensor IV. Fonte: http://www.intox.com.

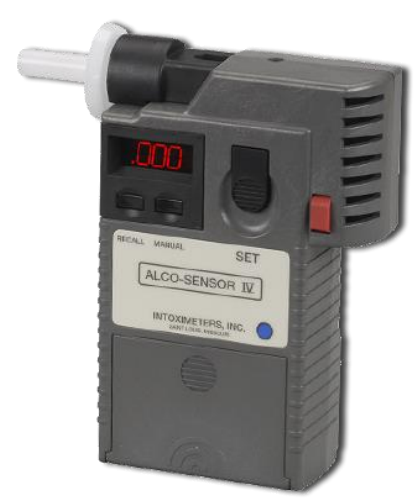

Esses equipamentos são mais sofisticados e fornecem dados numéricos que determinam com muita precisão a quantidade de álcool presente no organismo. Esses modelos de etilômetro baseiam-se no princípio das células de combustível.

O princípio das células a combustível foi descoberto por Sir Groveem 1835 (WENDT et al., 2000), cujo objetivo é utilizar um combustível e gerar energia elétrica 
de forma mais limpa e ecológica, praticamente sem emissão de poluentes. Existem diversos tipos de células de combustível e cada uma possui um objetivo particular. Essas células são classificadas de acordo com seu eletrólito e sua temperatura de funcionamento.

A célula de combustível utilizada no etilômetro oxida o etanol presente no ar e gera energia. Ela é formada por uma camada porosa, não reagente, coberta por duas placas de platina umedecidas com ácido sulfúrico $\left(\mathrm{H}_{2} \mathrm{SO}_{4}\right)$. Dois eletrodos são conectados às placas, formando um ânodo, no qual ocorre a oxidação, e um cátodo, no qual ocorre a redução. A platina em contado com o $\mathrm{H}_{2} \mathrm{SO}_{4}$ oxida o etanol a aldeído fazendo-o perder elétrons, e o oxigênio contido no ar será reduzido, pois irá receber os elétrons do etanol. Entre os eletrodos, o fluxo de elétrons é quantificado pelo medidor de corrente e um chip é capaz de informar o grau alcoólico do indivíduo de acordo com a corrente elétrica gerada com a reação de oxirredução (BRAATHEN, 1997).

A seguir é apresentada uma ilustração do processo que ocorre em uma célula combustível utilizada no etilômetro.

Figura 3: Processos químicos em uma célula combustível do etilômetro. Fonte: autor.

Ilustração do bafômetro baseado nas células combustiveis

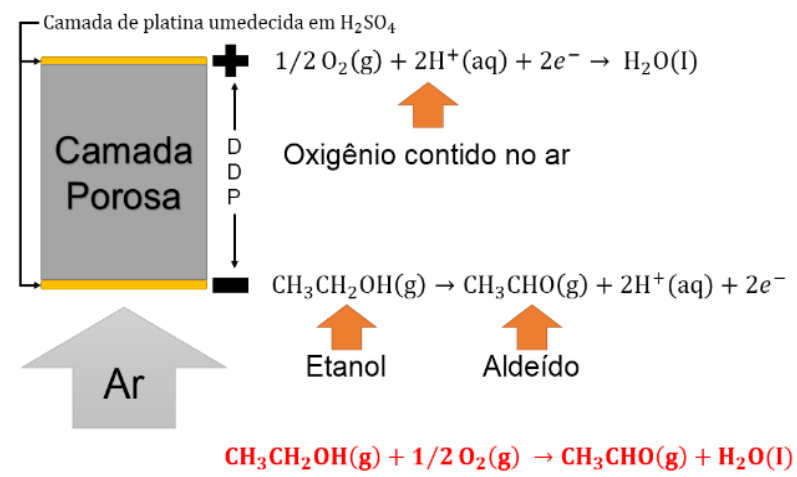


Os etilômetros quantitativos apresentam resultados precisos, e esse foi um dos motivos de sua escolha para ser utilizado pela polícia brasileira. Apesar de sua confiabilidade, assim como todo equipamento de medição, o etilômetro apresenta uma incerteza no processo de medidas. Para garantir a qualidade e veracidade de seus resultados, anualmente o Instituto Nacional de Metrologia, Qualidade e Metrologia (INMETRO), realiza uma inspeção no equipamento calculando o seu erro máximo. O equipamento é aprovado se apresentar um erro máximo de 0,032 mg/L para concentrações de até 0,400 mg/L, 8\% para os intervalos entre 0,400 mg/L e 2,000 mg/L, e de até 30\% em concentrações superiores a 2,000 mg/L (INMETRO, 2015).

\section{RESULTADOS E DisCUSSÃO}

\subsection{A EXPLORAÇÃO DO TEMA EM SALA de AULA}

As Diretrizes Curriculares Nacionais da Educação Básica determinam que "os princípios pedagógicos da identidade, diversidade e autonomia, da interdisciplinaridade e da contextualização são adotados como estruturadores dos currículos" (BRASIL, 2013, p. 154). Ao utilizar o etilômetro como temática para discussão de conceitos durante uma aula, o professor está inserindo um tema de extrema importância com capacidade de despertar a curiosidade do estudante para compreender a sua funcionalidade. Diversos são os conteúdos científicos que podem ser explorados pelo professor ao levar o tema para sala de aula.

No campo da Biologia, o metabolismo humano pode ser abordado em consonância com as discussões sobre o etilômetro. No etilômetro, a medição é feita a partir do ar expelido dos pulmões, o que permite discussões sobre o sistema respiratório e outros sistemas, que junto a esse, como o digestivo e o circulatório, são responsáveis pela eliminação do álcool ingerido. O tema estruturador proposto no PCN para Biologia, Qualidade de vida das populações humanas (PCNEN, 2002, p. 41), pode ser contemplado nessa discussão, uma vez que o consumo excessivo de bebidas 
alcoólicas tem se tornado umas das alternativas de lazer entre os jovens, resultando no aumento do índice de acidentes envolvendo bebida e direção. Os distúrbios que o etanol ocasiona no organismo, assim como sua absorção, são assuntos interessantes que podem vir a ser tratados pelo professor, construindo a noção de saúde levando em conta os condicionantes econômicos e culturais como: estilo de vida, estado nutricional e possibilidade de lazer.

Em Química as reações químicas se tornam evidentes. No PCN, um dos temas estruturados para o ensino de Química é: Energia e transformação química (PCN, 2002, p. 94). Com isso, é totalmente viável abordar, tendo como tema o etilômetro, os processos de oxirredução, a conservação da energia no processo de oxirredução, e a transferência de elétrons entre compostos químicos. Além disso, a experimentação pode ser utilizada, uma vez que alguns etilômetros qualitativos podem ser construídos e testados em laboratórios didáticos. Nesse sentido, Ferreira e colaboradores (1997) relatam a construção de um etilômetro simples de análise qualitativa para a sala de aula. Basicamente, o experimento é feito molhando dicromato de potássio em uma solução ácida aquosa (ácido sulfúrico) para melhorar a troca de elétrons com etanol. Após o contato do álcool com o dicromato de potássio, ocorre o processo de oxirredução, tornando visível a mudança na coloração no composto químico (FERREIRA et al., 1997).

A quantidade de álcool presente em bebidas alcoólicas é dada em uma escala denominada "Grau GL". Essa simples denominação pode fomentar uma discussão a respeito da história da ciência em sala de aula, evidenciando a descoberta de Gay Lussac, no século XVIII sobre o cálculo estequiométrico. Por exemplo, pode-se evidenciar que um recipiente contendo 1 litro de bebida destilada com uma graduação alcoólica de $38 \mathrm{GL}$, apresenta $380 \mathrm{ml}$ de álcool puro em sua composição. Infelizmente, uma parcela significativa dos estudantes não sabe fazer essa interpretação. 
Outra área crucial para o conhecimento científico que pode ser explorada está relacionada às transformações de unidades de medidas, que geralmente acabam sendo um obstáculo na aprendizagem do estudante. O professor pode verificar as unidades de medidas utilizadas nos etilômetros e nos boletins policiais e trabalhar com os estudantes as devidas transformações para o Sistema Internacional de Unidades.

Em Física, a eletrodinâmica pode ser destacada e conceitos sobre diferença de potencial na célula combustível, energia potencial elétrica e geração de corrente elétrica. Nas residências brasileiras a maior parte da energia elétrica provém de usinas, e a corrente elétrica que percorre os fios provém de alterações do campo eletromagnético em bobinas de fio de cobre. Os etilômetro modernos fornecem dados relacionados à embriaguez analisando uma corrente elétrica gerada por reações de oxirredução. Embora se tratem de processos distintos, ambos possuem em comum a geração de energia elétrica envolvendo transferências de elétrons. O professor pode fazer uso desses argumentos nas aulas sobre eletricidade, auxiliando o estudante a compreender que energia elétrica pode ser gerada de diversas formas, seja em usinas, pilhas ou células de combustível. A associação o estudo da eletricidade com funcionamento do etilômetro se enquadra no tema estruturador, citado no PCN, para a área de Física: Equipamentos elétricos e telecomunicações (PCNEM, 2002, p. 72).

No estudo da Matemática, os cálculos relacionados ao nível de álcool no sangue podem ser discutidos a partir do etilômetro. Soares (2014) atrela a modelagem matemática, com a utilização de função afim, para o cálculo da concentração de álcool no sangue. Equações sobre a alcoolemia são apresentadas e a partir de dados do decrescimento dessa taxa em função do tempo, é generalizada uma função afim para cálculos sobre o tempo que certa quantidade de álcool ingerido ficará no organismo da pessoa. O desenvolvimento dessa atividade em sala de aula pode mostrar para os estudantes que o álcool contido em uma única lata de cerveja pode demorar cerca de sete horas para ser eliminado do organismo. Esse tipo de conhecimento pode 
fomentar discussões importantes, em ciclos não escolares, a respeito do uso de bebidas e direção de veículos automotores.

Muitos desses tópicos são abordados em grande parte do ensino médio e nem sempre são trabalhados integrados a outras disciplinas. Entretanto, pode-se observar a orientação dos PCNEN para o ensino de Física que diz:

[...] as competências para lidar com o mundo físico não têm qualquer significado quando trabalhadas de forma isolada. Competências em Física para a vida se constroem em um presente contextualizado, em articulação com competências de outras áreas, impregnadas de outros conhecimentos. Elas passam a ganhar sentido somente quando colocadas lado a lado, e de forma integrada, com as demais competências desejadas para a realidade desses jovens. (PCNEN, 2002, p. 59).

\section{CONSIDERAÇÕES FINAIS}

De acordo com estudo da Faculdade Latino Americana de Ciências Sociais (ACSELRAD et al., 2012), as escolas temem abordar o assunto das drogas e os professores, apesar de buscarem uma formação sobre o tema, se sentem despreparados para fomentar tal discussão, ou temem falar de um tópico que deveria ser discutido em família.

Correlacionar o funcionamento desse equipamento ao estudo de um determinado tema pode ser uma experiência sem precedentes para o estudante. Conceitos físicos, químicos, biológicos, matemáticos e históricos podem ser abordados de maneira contextualizada, despertando a curiosidade do discente. O assunto também pode ser abordado como uma ação educativa para a conscientização quanto o uso alarmante de drogas entre os jovens.

Atrelar atividades interdisciplinares ao assunto em questão surge como uma estratégia fundamental para a formação de um cidadão capaz de desenvolver um olhar crítico em relação aos acontecimentos sociais e utilização de tecnologias. 
O etilômetro é uma tecnologia nova, inserida no dia a dia e de grande importância social. Tamanho é o seu destaque e relevância que o tema da redação do ENEM em 2013 foi "Os efeitos da Lei Seca no Brasil", e de forma correlacionada estava o uso do etilômetro (BRASIL, 2018). A discussão de assuntos atrelados a essa temática em sala de aula poderia ter sido muito útil aos estudantes que tiveram que discorrer sobre o tema nessa redação.

Espera-se que esse artigo sirva como norteador para que professores engajados possam fazer uso do tema em suas atividades de modo a possibilitar a articulação de ações e projetos interdisciplinares e de certa forma melhorar a qualidade das discussões sobre ciência dentro do ambiente escolar. 


\section{REFERÊNCIAS}

ACSELRAD, G. et al. Consumo de Bebidas alcoólicas no Brasil: estudo com base em fontes secundárias. FACULDADE LATINO AMERICANA DE CIÊNCIAS SOCIAIS. Rio de janeiro, 2012. 162p.

BRAATHEN, P. C. Hálito culposo e o princípio químico do bafômetro. Química Nova na Escola, v. $5,1997$.

BRASIL. Diretrizes Curriculares Nacionais da Educação Básica. Ministério da Educação. Secretaria de Educação Básica. Diretoria de Currículo e Educação Integral. Brasília - DF: MEC, SEB, DICEI, 2013. 562 p.

BRASIL. Parâmetros Curriculares Nacionais. Ministério da Educação. Secretaria de Educação Média e Tecnológica. Brasília: MEC, 2000. 109p.

BRASIL. Parâmetros Curriculares Nacionais; ensino Médio. Ministério da Educação. Secretaria de Educação Média e Tecnológica. Brasília - DF: MEC, 2002. 141p.

BRASIL. Lei Federal n. 13.546 de 19 de dezembro de 2017 - Altera dispositivos da Lei n 9.503, de 23 de setembro de 1997 (Código de Trânsito Brasileiro), para dispor sobre crimes cometidos na direção de veículos automotores.Diário Oficial da União, Poder Executivo, Brasília, DF, 20 de dezembro de 2017.

BRASIL. Lei Federal n. 9.503 de 23 de setembro de 1997 - Institui o Código de Transito Brasileiro.Diário Oficial da União, Poder Executivo, Brasília, DF, 24 de setembro de 1997.

BRASIL. Instituto Nacional de estudos e Pesquisas Educacionais Anísio Teixeira. Redação aborda efeitos da implantação da Lei Seca no Brasil. Disponível em: <http://portal.inep.gov.br/artigo/-/asset_publisher/B4AQV9zFY7Bv/content/redacaoaborda-efeitos-da-implantacao-da-lei-seca-no-brasil/21206>. Acesso em 26/02/2018.

Doenças do Fígado, 2018.2 Disponível em: <http://ftp.medicina.ufmg.br/omenu/materiais/intervencoes/doencas_do_figado_11 072014.pdf>. Acesso em: 21/01/2018.

DATASUS. Estatísticas nacionais de mortos em acidentes de trânsito. Disponível em: <http://www.vias-seguras.com/os_acidentes/estatisticas/estatisticas_nacionais>. Acesso em 08/11/2018.

BREATHALYSERS IN HISTORY. Disponível em: <https://www.drinkdriving.org/drink_driving_information_breathalysers_early.php>. Acesso em 18/01/2018.

FERREIRA, G. A. L; MÓI, G.S; SILVA, R. R. Bafômetro - Um Modelo Demonstrativo. Química Nova na Escola, v.5, 1997. 
GOVERNO DO RIO DE JANEIRO. Operação Lei Seca completa 8 anos de atuação. In: Noticias.

<http://www.rj.gov.br/web/guest/exibeconteudo;jsessionid=F90F8BDC40F058CDD67 44D0A55368EE0.Iportal2?p_p_id=exibeconteudo_INSTANCE_2wXQ\&p_p_lifecycle $=0$ \&refererPlid=11702\&_exibeconteudo_INSTANCE_2wXQ_struts_action=\%2Fext\%2Fex ibeconteudo\%2Frss\&_exibeconteudo_INSTANCE_2wXQ_groupld=103138\&_exibecon teudo_INSTANCE_2wXQ_articleld=3084241>. Acesso em: 02/11/2017.

INMETRO. Procedimento para verificação e inspeção de etilômetro com gás seco. Disponível em: <http://www.inmetro.gov.br/ftp_hp/kits/nie-dimel-108r02.pdf>. Acesso em: 10/12/2017.

KRASILCHIK, M. Caminhos do ensino de ciências no brasil. Em Aberto, Brasília, v. 11, n. 55, p.3-8, 1992.

LEAL, M. C.; ARAÚJO, D. A.; PINHEIRO, P. C. Alcoolismo e Educação Química. Química Nova na Escola, v. 34, n. 2, p. 58-66, 2012.

PERRENOUD, F. Dez novas competências para ensinar. Trad: Patrícia Chittoni Ramos. Porto Alegre: Artmed, 2000. 192p.

SOARES, C. A. Modelagem por meio de Funções Elementares. 2014. 79f . Dissertação (Mestrado Profissional em Matemática) Universidade Federal de Goiás, Catalão, 2014.

SOUZA, G. Q. Álcool e adolescência: um estudo aplicado ao ensino de Química. 2014. 62 f. Trabalho de conclusão de curso (Licenciatura em Química). Universidade Estadual da Paraíba. Campina Grande - PB, 2014.

WENDT, H.; GÖTZ, M.; LINARDI, M. Tecnologia de células a combustível. Química Nova, v. 23, n. 4, p. 538-546, 2000. 